\title{
Classical Ehlers-Danlos syndrome
}

INSERM

\section{Source}

INSERM. (1999). Orphanet: an online rare disease and orphan drug data base. Classical Ehlers-Danlos syndrome. ORPHA:287

Ehlers-Danlos syndrome, classic type (CEDS) is a form of Ehlers-Danlos syndrome that affects the connective tissue and is characterized by skin hyperextensibility, widened atrophic scars and joint hypermobility. 